\title{
BMJ Open Qualitative interview study exploring the patient experience of living with axial spondyloarthritis and fatigue: difficult, demanding and draining
}

\author{
Nathan Ashley Pearson (D) ,' Elizabeth Tutton (D) ,, ${ }^{1,2} \mathrm{~J}$ Martindale, ${ }^{3,4}$ \\ George Strickland, ${ }^{5}$ Jean Thompson, ${ }^{5}$ Jonathan C Packham, ${ }^{6,7}$ Paul Creamer, ${ }^{8}$ \\ Kirstie Haywood ${ }^{1}$
}

To cite: Pearson NA, Tutton E, Martindale J, et al. Qualitative interview study exploring the patient experience of living with axial spondyloarthritis and fatigue: difficult, demanding and draining. BMJ Open 2022;12:e053958. doi:10.1136/ bmjopen-2021-053958

- Prepublication history for this paper is available online. To view these files, please visit the journal online (http://dx.doi org/10.1136/bmjopen-2021 053958).

NAP and ET are joint first authors.

Received 28 May 2021

Accepted 04 February 2022

Check for updates

(c) Author(s) (or their employer(s)) 2022. Re-use permitted under CC BY-NC. No commercial re-use. See rights and permissions. Published by BMJ.

For numbered affiliations see end of article.

Correspondence to Dr Nathan Ashley Pearson; nathan.pearson@warwick.ac.uk

\section{ABSTRACT}

Objective To explore patients' lived experiences of axial spondyloarthritis (axSpA) and fatigue.

Design Interpretative phenomenological analysis (lived experience) was used as the study design. Analysis drew together codes with similar meaning to create superordinate and subordinate themes.

Setting Rheumatology departments in three National Health Service Foundation Trusts in the north, midlands and south of England.

Participants A purposive sample of seventeen axSpA patients were recruited. The age range was 22-72 years (median age 46), nine were male and eight, female. Results A central concept of achieving balance was identified as the active process of integrating axSpA symptoms and fatigue into daily life, working with and not against their condition to lead a fulfilled life. This was conveyed through three superordinate themes: struggling to find energy, engaging in everyday life and persevering through difficulties. Struggling to find energy was the challenge of retaining enough stamina to do things in daily life. Engaging in everyday life highlighted dedication to being active and organised, learning through experience and acceptance of a changed way of being. Persevering through difficulties identified the physical and emotional effort required to keep moving forward and the importance of feeling supported.

Conclusion Achieving balance through finding energy, engaging and persevering everyday was fundamental to having the best possible life. The experience of energy emerged as a distinct but related component of fatigue. However, while energy could be maintained or replenished, fatigue was more difficult to overcome and required greater effort. Energy may be a useful indicator of an individual's current state and ability to sustain activities that supports their well-being, such as exercise. Awareness of the elements of achieving balance in axSpA may enable patients and clinicians to work together to tailor treatments to individual patient need.

\section{INTRODUCTION}

Axial spondyloarthritis (axSpA) is an incurable, inflammatory rheumatological condition that primarily affects the axial skeleton. ${ }^{12}$
Strengths and limitations of this study

- Using interviews provided rich data and supported identification of energy as a related but distinct aspect of the fatigue experience that needs to be managed to enable patients to achieve balance between daily living and their condition.

- Involving patients as research partners has focused findings on issues of importance to patients, facilitating the formation of key themes to be considered by health professionals in the provision of future care and support.

- Future research that captures the ethnic diversity of patients may extend the transferability of the findings.

- The inclusion of healthcare professionals would situate the process of achieving balance within the context of care.

Cardinal features of axSpA include pain, stiffness, reduced mobility and fatigue. ${ }^{34}$

Fatigue has been identified as an important symptom for axSpA patients and was recently rated as one of the top three symptoms that patients wanted to see addressed. ${ }^{5} \mathrm{Up}$ to $66 \%$ of axSpA patients report having fatigue, ${ }^{6}$ of whom up to $75 \%$ report experiencing severe fatigue. ${ }^{7}$ However, understanding of the experience of fatigue in axSpA is limited to a small number of descriptive studies from the UK, ${ }^{8} \mathrm{USA}^{10}{ }^{10}$ Norway, ${ }^{11}{ }^{12} \mathrm{Egypt}^{13}$ and a review of fatigue experience which included axSpA. ${ }^{14}$ These studies portray axSpA-fatigue as a complex condition that includes physical and mental fatigue, ${ }^{8}$ is different from normal tiredness, ${ }^{8}$ is unpredictable, ${ }^{12}{ }^{14}$ can be affected by the weather or overexertion, ${ }^{11}$ and leads to a reduction in social engagement. ${ }^{8}$ Two studies conducted in Norway showed a distinction between normal tiredness and illness-related fatigue. ${ }^{11} 12$ 
These studies clearly highlight the importance of fatigue to axSpA patients. However, the focus of these studies has often been to specifically examine causes of fatigue, ${ }^{813}$ self-management, ${ }^{89}$ or to inform the development and modification of an existing questionnaire. ${ }^{10}$ This narrow focus means we know little about how axSpA may modulate the fatigue experience, and vice versa, or how patients balance these two aspects of their condition. Moreover, the studies lack methodological clarity and have typically sampled few (if any) young adults. There is a gap in knowledge about how younger adults, early in their diagnosis, experience fatigue and axSpA. Therefore, further understanding of what is important to patients in their daily life with a defined sample and method is required. The aim of this study was to explore patients' lived experience of axSpA and fatigue within their daily life.

\section{PATIENTS AND METHODS}

This study drew on interpretative phenomenological analysis which provides methodological direction for research that focuses on understanding the lived experience of others. ${ }^{15}$ This approach enabled participants to share their everyday life experiences of axSpA and fatigue within their cultural and social context. The researcher aimed to gain an 'insider perspective' ${ }^{16}$ focusing on what was said to develop insights into what it is like to live with, and how participants made sense of their experience of axSpA and fatigue. ${ }^{15}$ Interpretations of meaning drawn from their experiences were made by the researchers in collaboration with patient research partners (PRPs). The researchers took a reflective stance, were aware of their own role and influence, and where necessary were challenged by PRPs to maintain the focus on what was important to patients.

\section{Patient and public involvement}

The study was conceived in collaboration with PRPs, of whom two were coapplicants on the funding grant. Two group meetings were held with five PRPs. The importance of understanding fatigue from the patient perspective was highlighted in meeting one, and an interview study and schedule developed collaboratively between the PRP members, and research team. PRP members were not involved in recruitment. Preliminary findings were discussed in meeting two, with members facilitating the development of the superordinate and subordinate themes, and insight into the meanings conveyed. Results will be shared as a summary for participants.

Informed written consent was obtained from all participants who received an information sheet and had at least 24 hours to consider their participation. Clinical staff approached patients and obtained written permission for the researcher to contact them.
Table 1 To show the characteristics of the sample

No of patients

\begin{tabular}{llc} 
Variables & & (total $\mathbf{n}=\mathbf{1 7}$ ) \\
\hline Sex & Male & 9 \\
& Female & 8 \\
Age & $18-30$ & 4 \\
& $31-40$ & 2 \\
& $41-50$ & 5 \\
& $51-60$ & 2 \\
& $61+$ & 4
\end{tabular}

\begin{tabular}{|c|c|c|}
\hline $\begin{array}{l}\text { BASDAI } \\
\text { AxSpA-specific } \\
\text { assessment of } \\
\text { disease activity }\end{array}$ & $\begin{array}{l}>4 \text { (high disease activity) } \\
\leq 4 \text { (low disease activity) }\end{array}$ & $\begin{array}{r}7 \\
10\end{array}$ \\
\hline $\begin{array}{l}\text { BASFI } \\
\text { AxSpA-specific } \\
\text { assessment } \\
\text { of functional } \\
\text { impairment }\end{array}$ & $\begin{array}{l}>4 \text { (high impairment) } \\
\leq 4 \text { (low impairment) }\end{array}$ & $\begin{array}{l}9 \\
8\end{array}$ \\
\hline \multirow[t]{2}{*}{ HADS anxiety } & $\begin{array}{l}>7 \text { (mild to severe } \\
\text { anxiety) }\end{array}$ & 8 \\
\hline & $\leq 7$ (normal anxiety) & 9 \\
\hline \multirow[t]{2}{*}{ HADS depression } & $\begin{array}{l}>7 \text { (mild to severe } \\
\text { depression) }\end{array}$ & 6 \\
\hline & $\leq 7$ (normal depression) & 11 \\
\hline
\end{tabular}

AxSpA, axial spondyloarthritis; BASDAI, Bath Ankylosing Spondylitis Disease Activity Index; BASFI, Bath Ankylosing Spondylitis Functional Index; HADS, Hospital Anxiety and Depression scale.

\section{Participants}

A purposeful sample of seventeen participants (nine male; mean age 45; median age 46; range 22-72) with diagnosed axSpA (mean diagnosis duration 14.4 years; range 1-42) were recruited from three secondary care rheumatology departments in England (by local clinical staff) and took part in interviews (mean duration $48 \mathrm{~min}$; median 48; range 22-86). To further describe the sample, demographic factors and disease-related information was obtained through recommended assessments ${ }^{17}$ of disease activity (Bath Ankylosing Spondylitis Disease Activity Index ${ }^{18}$ ), functional limitations (Bath Ankylosing Spondylitis Functional Index ${ }^{19}$ ) and mood (Hospital Anxiety and Depression scale ${ }^{20}$ ). These were administered at the end of the interview and were not used as screening data but to describe the range of disease severity in the sample. Sampling characteristics (table 1) were recorded iteratively following interviews and used to facilitate purposive sampling.

\section{Interviews}

Digital audiorecorded, semistructured interviews were conducted with English-speaking patients with a primary diagnosis of axSpA. ${ }^{21}$ The interviews were undertaken by 
Box 1 To show the interview guide co-produced with the patient partners

\section{Question}

What is living with axSpA like for you?

What happens if your axSpA gets worse?

Do you experience any fatigue?

How would you describe your fatigue?

What does 'fatigue' or 'tiredness' mean to you?

What do you think causes your fatigue?

What effect does fatigue have on your daily life? (Prompts: work, relationships, family)

Did/do you make any changes to your daily routine?

How do you deal with your fatigue?

How do you look after yourself when you are experiencing the fatigue?

What works best for you to manage the fatigue?

Is your fatigue discussed during your visits with healthcare professionals? (eg, physiotherapists, doctors)

What are the things that you would like a healthcare professional to ask you about when discussing fatigue?

NAP, face to face, in a private room at the participant's local rheumatology clinic. The participants were not known prior to the interview. An initial interview guide was coproduced with PRPs and is presented in box 1 . Data analysis was conducted iteratively, this enabled new codes such as 'being full of energy' to be explored further using open questions in future interviews. Reflexive notes were made following interviews to aid analysis.

\section{Analysis}

Data analysis followed the six-step process described by Smith et al, ${ }^{15}$ NVivo V.10 software was used to manage the study data. ${ }^{22}$ In step 1 , immersion in each patient's lived experience was achieved through conducting and transcribing the interviews followed by reading and rereading the transcripts. Exploratory notes were made in step two examining experiences, meanings and language. Using these notes, emergent themes were identified in step three. Key concepts, relationships between them and patterns within the participants data were identified in step 4 . In step 5, these processes were repeated for each participant. Finally, step 6 involved looking for patterns between participants. For example, explanatory notes identified ideas or codes such as 'lacking stamina', and 'no energy' which were drawn together and incorporated into the emergent theme 'being drained'. Being drained was noted across all participants' transcripts within the context of activity, alongside the concept of energy and was thus refined to 'lacking energy'. This became a subordinate theme in the analysis and was combined with a second subordinate theme 'finding ways to preserve stamina and re-energise' to create the superordinate theme 'struggling to find energy'.

The analysis was inductive and conducted iteratively, individual participant's experiences were drawn together to present an overarching understanding of the experience of axSpA and fatigue. NAP undertook the analysis with regular discussions with ET who coded 5 interviews and, together with the PRP group and research team, developed the themes. At the time of conducting this study, NAP (a male doctoral student) had a background in psychology and cognitive neuroscience and was new to axial SpA research. ET is an experienced female qualitative researcher in health sciences research. Rigour ${ }^{23}$ was demonstrated through commitment to each individual and the significance of their story. A detailed audit trail of themes, definitions with illustrative quotes is provided in table 2, showing theme derivation. Transparency was demonstrated through description of the methods, identification of the research setting (rheumatology) and positionality of the researchers. To ensure anonymity each participant was allocated a number from 1 to 17 .

\section{RESULTS}

\section{Findings}

The findings identify the central concept of 'achieving balance'. Achieving balance was the active process of integrating axSpA symptoms and fatigue into their world, working with and not against their condition, to lead the best possible life. Participants experienced their lives and symptoms as unpredictable, often feeling drained of energy and experiencing pain and stiffness. However, they worked hard to find energy, engage with everyday life, and persevered to move forward. Achieving balance was conveyed through three superordinate themes: (1) 'struggling to find energy' with subordinate themes of 'lacking in energy', and 'finding ways to preserve stamina and re-energise'; (2) 'engaging in everyday life' with subordinate themes of 'being active and organised' and 'changed ways of being'; and (3) 'persevering through difficulties' with subordinate themes of 'striving to maintain normal life' and 'feeling supported'. The themes are represented in figure 1 and table 2 .

\section{Superordinate theme 1: struggling to find energy}

Struggling to find energy conveyed the challenge participants experienced in trying to gather, preserve and use their often limited energy levels to live fulfilled lives. Participants identified their lack of energy and worked hard to maintain a degree of stamina. This was expressed through two subordinate themes: lacking in energy and finding ways to preserve stamina and re-energise.

\section{Lacking in energy}

Lacking in energy was expressed as the experience of being drained and having trouble beginning or continuing an activity. Being drained of energy affected participants both physically and mentally and became a barrier to activity initiation and maintenance. The experience of being drained followed a sudden loss of energy which often resulted in plans being changed or cancelled.

I can't be bothered doing owt (to do anything). Or anything that involves getting up and moving around. Anything remotely active. (P10) 


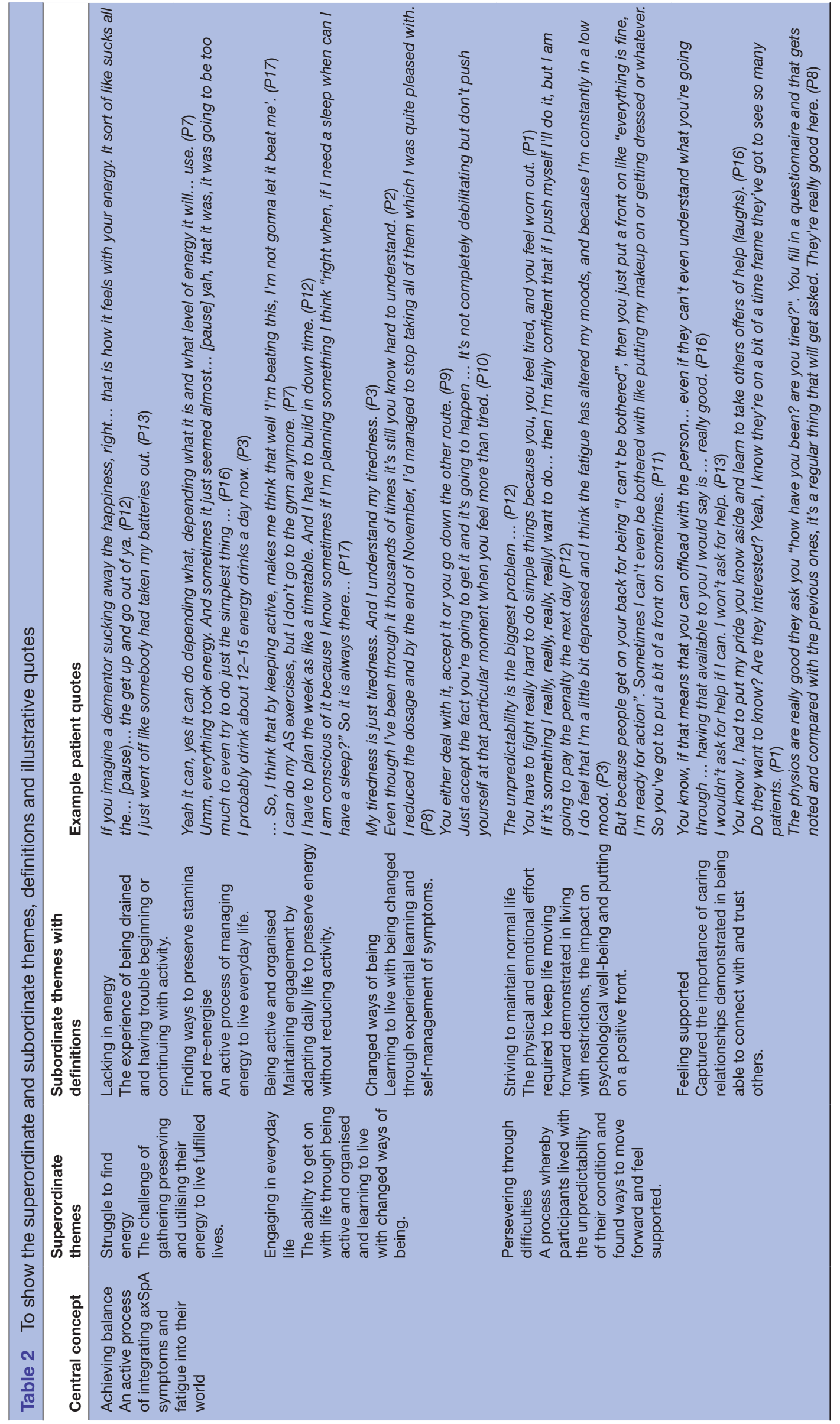




\section{Achieving Balance}

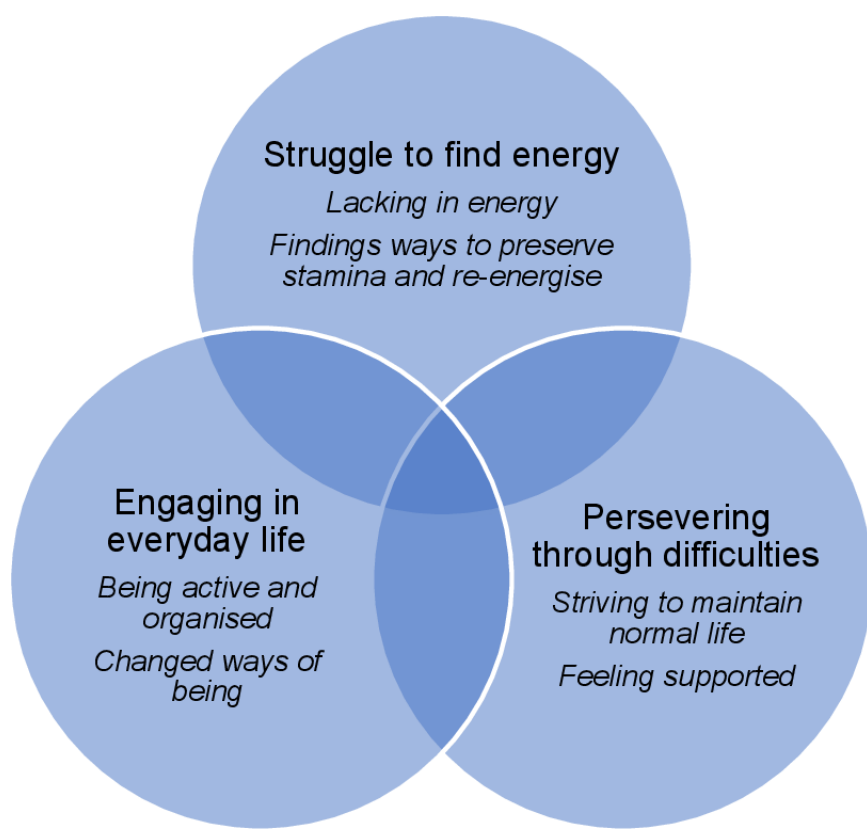

Figure 1 Presentation of the superordinate and subordinate themes for achieving balance.

Pain from axSpA amplified these difficulties, reducing their capacity to get going.

I can go from one min I'm walking around fine to the next minute in a lot of pain and you just start feeling lethargic and kind of like you're running out of steam. (P9)

When energy needs became too great to be active, many participants felt resigned to inactivity, to seek relief. They described energy as a resource used to initiate and maintain physical and mental activity.

I would say energy is different [to fatigue] ... you need energy to be able to do anything. (P16)

\section{Finding ways to preserve stamina and re-energise}

Finding ways to preserve stamina and re-energise was an active process of managing their energy to enable them to live everyday life. Preserving enough energy for the day was difficult and participants often adjusted their plans to manage their stamina to get through the day. Participants were not always adept at this. Processes such as task appraisal and task avoidance to avoid energy over expenditure and support efforts to preserve energy were used.

So, so I try and avoid things. Try keep myself full of energy but I try and avoid things that are going to make myself feel bad. (P3)

Failure to preserve energy could interfere with tasks, requiring extra effort to perform activities, thus further depleting already diminished energy levels. Finding effective ways to re-energise was difficult for participants, with methods including regular rest breaks, adopting a healthier diet and for some, a more extreme reliance on excessive consumption of high sugar/caffeinated drinks to quickly re-energise and keep going.

I nap every day. Every single day. And then again I don't know if that makes me feel better psychologically. (P7)

I'll still have a drink of water or whatever, try and, orange juice and try re-energise. (P5)

Despite highlighting that these approaches were mostly unreliable, they did enable individuals to keep going; particularly when common advice to rest or sleep when feeling drained was difficult to reconcile with work and life commitments.

\section{Superordinate theme 2: engaging in daily life}

Engaging in everyday life captured two important processes that enable participants to get on with and maintain daily life. This was conveyed through two subordinate themes: (1) being active and organised, and (2) changed ways of being.

\section{Being active and organised}

Being active and being organised were processes that enabled participants to maintain engagement in daily life by adapting their approach to preserve their energy without having to reduce activity. This involved managing exertion and using routine.

Participants were determined to keep moving and changed activities to find a compromise between their symptoms and degree of activity. Compromise was key, enabling participants to balance exercise (to alleviate axSpA symptoms) with maintaining their energy levels. Altered perceptions of time could leave participants feeling as though fatigue had shrunk their world and meant they were less able to be impulsive, necessitating organisation.

If I wasn't as fatigued I know I would be out doing more and just going about my day but fatigue ... restricts that to only a few hours a day maybe at most. (P4)

Planning made it easier to complete more complicated activities. This helped participants to find a balance between over and under-exertion. Those who adopted a flexible approach were better at handling these issues, while others adopted a defiant attitude and pushed through, irrespective of any payback they might experience.

I'll plan particularly carefully that I'm not doing too much. I'll particularly plan I'm not doing anything too little ... I will not push it too far anymore, very much in terms of my daily life. It's within limits. (P10)

Routine was part of this process and allowed them to incorporate activities into daily life in a systematic way, introducing structure and ensuring prioritisation of essential tasks. 


\section{Changed ways of being}

Changed ways of being identified how participants adapted to incorporate their symptoms and fatigue into their life through experiential learning and learning to self-manage symptoms.

Experiential learning was a process of developing knowledge, enabling participants to distinguish between fatigue and normal tiredness, identify the type of fatigue and how it will affect them, and understand patterns within their experience. Participants could 'feel' the difference.

I don't think you can compare the two. With tiredness I just look forward to going to bed, and with my fatigue I could climb into bed in the middle of the afternoon and be asleep within 10 seconds. (P7)

Participants described physical fatigue as a whole-body experience that left them feeling heavy. Mental fatigue was described as having 'brain fog' (P12) and being 'drunk with tiredness' (P7). These metaphors provide insight into how fatigue can manifest as sensations and have a hazing effect on cognitive functions, expressed as challenges with concentrating, staying focused on tasks and slurred speech during social interactions.

Learning to self-manage symptoms was achieved through a process of trial-and-error, complemented by increased self-awareness, and 'knowing' their body. Selfmanagement needs and decisions varied depending on symptoms, difficulties with energy levels and feelings of fatigue. However, many highlighted that they did not know what to do for their fatigue.

I don't really know what to do. Apart from like curling up in bed I don't really know what to do. I find that hard cos I don't know what to do to manage it. (P2)

Acceptance of illness, feelings of fatigue and low energy was key. Being accepting was a sense of becoming comfortable with the condition and working with, rather than against it by keeping it in perspective.

You either deal with it, accept it or you go down the other route. (P9)

\section{Superordinate theme 3: persevering through difficulties}

Persevering through difficulties was a process whereby participants lived with the unpredictability of their condition and found a way to move forward. This was conveyed through the subordinate themes, striving to maintain normal life, and feeling supported.

\section{Striving to maintain normal life}

Striving to maintain normal life reflects the physical and emotional effort required to keep life moving forward demonstrated in living with symptoms, living with restrictions, the impact on mental well-being and putting on a positive front.
AxSpA symptoms, feelings of fatigue and energy levels often fluctuated, including periods of symptom flare with increased pain, stiffness, and fatigue. This unpredictability meant it was difficult to mitigate the extent of the impact of their symptoms on their daily life.

The unpredictability is the biggest problem. (P12)

The influence of pain on fatigue was unclear, with some suggesting it caused fatigue, while others felt it amplified feelings of fatigue.

The pain does make the fatigue worse because you're looking for an escape, from the pain. (P1)

Restrictions from axSpA and fatigue could necessitate extra effort to complete even basic actions; for example, normal movements could require extra actions, quickly culminating in greater energy expenditure.

Makes me put so much more effort into doing things that I wouldn't have to think twice about doing before. (P3)

This can further diminish energy levels, disrupt energy maintenance efforts and lead to overexertion and payback. 'Payback' (a period of prolonged recovery during which participants felt worse than normal) was a distinct component and could follow overexertion for even minor activities (eg, meeting a friend for coffee).

Participants disclosed feelings of anxiety, guilt, and downturns in mood attributable to fatigue. Many described a toll on their mental health stating they felt depressed, low, and fed up.

It does make you feel very low and yet I'm not a depressive person at all. I'm a very happy person, sociable person. (P13)

This toll could influence temperaments, leaving some participants feeling more irritable and short-tempered which subsequently affected their relationships with others. Participants described feeling guilty for two reasons: putting their own fatigue needs ahead of the perceived needs of others, and when having to abandon plans last minute.

It's just very quick tempered, very quick to bite back. Whereas normally I'm quite a chilled-out person. So it does affect my home life. (P3)

Emotional containment was an important mechanism that helped participants to disconnect from their condition and move it into the background. For some, this was sometimes part of a denial of symptoms and avoidance of others. For most, presenting a positive front was used to protect themselves or those around them.

If I'm tired or fatigued or if I'm in a lot of pain, I just put a smile on and crack on you know (laughs), because why should you bother other people with your ailments. (P1) 


\section{Feeling supported}

Feeling supported captured the importance of caring relationships demonstrated in being able to connect with, and trust others. Participants drew on support from others for physical tasks, to talk to and share their experience and feelings.

If that means that you can offload with the person ... even if they can't even understand what you're going through... having that available to you I would say is... really good. (P16)

Good understanding and empathy from others were positively received by participants. However, others who did not understand or challenged the veracity of their experiences became a barrier to participants seeking support.

Sharing experiences depended on a trusting relationship. Participants who described lacking trust also highlighted greater tension in their relationships, which they often attributed to the other party. However, those who understood their condition and its link to fatigue were often more open about their experiences and described more reciprocal interactions with others. Challenges existed in interactions with clinicians, with participants worried that their fatigue would be brushed off, overlooked, or disregarded, potentially due to perceived time constraints. Some did not discuss fatigue because of these concerns.

If I brought it up and wanted it addressed, and they just brushed over it. As in 'oh that tired thing, let's move on'. (P3)

Do they want to know? Are they interested? ... I know they're pretty busy and you think 'am I wasting their time?'. (P1)

Receptiveness and proactivity from professionals were reassuring and led to an openness, empowering the participant to disclose uncomfortable, uncertain, and tentative issues that were affecting them.

I know I can say stuff to [name]... and she'll listen and give good advice... much more than most other people will. (P12)

\section{DISCUSSION}

A major finding from this study is the importance of achieving balance in the context of axSpA and the impact of fatigue: this reflects the work undertaken by patients to self-manage their condition, cope with their fatigue and its effects, and maintain their energy. This extends current knowledge $\mathrm{e}^{8-13}$ and highlights the burden of axSpA and fatigue on mental well-being. This study identified the importance of: (1) the concept of energy as a related but distinct component of fatigue experience, (2) the development of expertise to enable self-management and, (3) perseverance due to the unpredictability of symptoms. Understanding how patients' experience fatigue may help patients and clinicians work together to tailor treatments and facilitate the development of expertise in achieving balance.

Energy emerged as a distinct but related concept to fatigue, a finding that corroborates other studies in HIV, ${ }^{24-28}$ and nephrology, ${ }^{29}$ but a distinction not previously identified in axSpA. In this study, energy was described as a short-term, daily resource that can be drawn on and replenished to sustain physical or mental activity. This definition builds on descriptions of energy in other specialities ${ }^{30}$ and challenges views that energy is the same as or opposite to fatigue. ${ }^{812-34}$ In this study, fatigue permeated all spheres of the participant's life, was unresponsive to rest or sleep, was unpredictable, uncontrollable, and derailed plans. This is similar to (but different from) the experience of fatigue in rheumatoid arthritis (RA). ${ }^{35-37}$ In RA, flares were commonly identified as a cause of fatigue, ${ }^{35}$ but in axSpA, fatigue was persistent, with flares amplifying the fatigue experience. Patients distinguished between normal tiredness (eg, that which occurs due to lack of sleep) and their feelings of fatigue which were unpredictable and did not follow a pattern, or a known cause. While tiredness could be alleviated by sleep, feelings of fatigue were more difficult to mitigate. Moreover, pain could disrupt sleep and activities, worsening fatigue. AxSpA patients described how they made practical, personal, psychological, social and environmental changes to maximise their engagement in daily life. This complex, multifaceted approach highlights the substantive toll of axSpA on patients as it permeates every sphere of their life and ways of being.

Managing fatigue and energy levels required participants to identify, develop and appraise different approaches to ease or self-manage their symptoms. Those who were adept at this demonstrated a learnt expertise. This expertise was often acquired over time through experiential learning, incorporating trial-and-error methods, which have been identified in other axSpA studies. ${ }^{8} 11$ Experiential learning enabled them to develop effective strategies tailored to their needs. However, patients can find it difficult to communicate their personal and emotional needs to clinicians. ${ }^{38}$ Research suggests that health professionals rarely discuss fatigue ${ }^{35}$ or refer patients to relevant support services. ${ }^{39}$ Moreover, different perspectives of fatigue between patients and clinicians link to poor outcomes, ${ }^{40}$ suggesting a need for effective patient-clinician communication. Our study highlighted that trusting relationships were enabling. Fostering these relationships may enable patients to instigate conversations about fatigue and mental well-being, supporting early identification and timely referral to relevant support services.

Perseverance and the ability to sustain moving forward despite unpredictability was key to living a fulfilled life. However, fatigue was often invisible to others, could impact on participants' mood, relationships and degree of engagement. Estimates for depression range between $11 \%$ and $64 \%$ in this group ${ }^{41}$ yet 
emotional and psychological well-being are not part of routine clinical assessment. ${ }^{17}{ }^{42}$ The National Axial Spondyloarthritis Society (NASS) bridge this gap by incorporating mental health support services into their patient support (https://nass.co.uk/about-as/ what-is-as/your-wellbeing/). This study identified that low mood could undermine feelings of self-efficacy, a key factor underlying healthy behaviour such as taking exercise, ${ }^{43}$ which is important for spinal mobility and function. ${ }^{44-46}$ Exercise can lead to better outcomes for disease activity, functional, pain and fatigue outcomes. ${ }^{47}$ A link between pain and fatigue was reported, with some describing pain as a cause or amplifier of fatigue. Well-managed pain could mitigate feelings of fatigue for some, which supports other findings in axSpA. ${ }^{48} 49$ Therefore, supportive interventions focused on mood and self-efficacy may promote individual's ability to persevere and achieve a balance despite the unpredictability of their condition.

The strengths of the study were that the focus on lived experience facilitated an exploration of energy, not previously highlighted in axSpA studies. Collaboration with PRP group members throughout the study enhanced our understanding of energy and stamina. The purposeful sample ensured a range of age which incorporated a larger cohort of younger adults and older adults, meaning that it was more representative of the wider axSpA population. ${ }^{50}$ Therefore, this study included some of the youngest and oldest participants in axSpA qualitative work to date. The study also described a wider range of disease durations than that reported in other studies, ${ }^{812}$ ranging from 1 to 42 years, and hence supporting the exploration of fatigue across a diverse range of participants. However, while axial SpA is a predominantly Caucasian condition, ${ }^{51}{ }^{52}$ the study does lack the insight of those from ethnic minorities who may have different experiences. Including professionals may have helped to situate the process of achieving balance with the context of care.

A range of challenges were discussed in this study attributable to axSpA, fatigue and energy. Achieving balance was key to having the best possible life. Energy emerged as a related but distinct component of fatigue experience; a resource necessary to be physically and mentally active, that can be replenished or maintained. Consequently, energy may be a useful indicator to assess the likelihood of patients being able to complete and maintain activities, such as a regular exercise regimen. Future research will focus on using this knowledge to underpin the development of a new patient-reported outcome measure for fatigue and energy in axSpA. Knowing the elements necessary to achieve balance may support patient-clinician interaction, allowing professionals to focus on key issues such as energy levels, expertise in self-management and mental health, thus improving patient outcomes.

\section{Author affiliations}

${ }^{1}$ Warwick Research in Nursing, University of Warwick, Coventry, UK
${ }^{2}$ Kadoorie, Oxford Trauma and Emergency Care, Nuffield Department Orthopaedics, Rheumatology and Musculoskeletal Sciences (NDORMS), University of Oxford, Oxford, UK

${ }^{3}$ Faculty of Health and Social Care, Edge Hill University, Ormskirk, UK

${ }^{4}$ Rheumatology, Wrightington Wigan and Leigh NHS Foundation Trust, Wigan, UK

${ }^{5}$ Patient Research Partners, Rheumatology, Wrightington Wigan and Leigh NHS

Foundation Trust, Wigan, UK

${ }^{6}$ Haywood Academic Rheumatology Centre, Midlands Partnership NHS Foundation

Trust, Newcastle-under-Lyme, UK

${ }^{7}$ Division of Epidemiology and Public Health, University of Nottingham, Nottingham, UK

${ }^{8}$ Rheumatology, North Bristol NHS Trust, Westbury on Trym, UK

Twitter Elizabeth Tutton @oxford Trauma and Emergency Care@oxford_trauma

Acknowledgements The authors would like to extend their thanks to NASS for supporting this project. We would also like to thank all the patients and informal carers who generously gave their time and energy to support this study. In addition, we would like to thank our patient research partners and all the staff who facilitated aspects of this study.

Contributors NAP is the guarantor. NAP and ET wrote the manuscript. The design and analysis were led by NAP with ET and KH. NAP undertook the data collection. NAP, ET, KH, JCP, JM, PC and our patient partners (GS, JT) were involved in the data analysis, data interpretation and discussion of the findings and all authors were involved in the development of this paper.

Funding This study was funded by the National Ankylosing Spondylitis Society (NASS) (Grant number: WAR1).

Competing interests No benefits have been received or will be received from a commercial party related directly or indirectly to the subject of this article.

Patient and public involvement Patients and/or the public were involved in the design, or conduct, or reporting, or dissemination plans of this research. Refer to the Methods section for further details.

Patient consent for publication Not applicable.

Ethics approval This study involves human participants and was approved by West Midlands - Black Country Research Ethics Committee (REC reference: 16/ WM/0147) and the Health Research Authority (approval dated: 22 April 2016). Participants gave informed consent to participate in the study before taking part.

Provenance and peer review Not commissioned; externally peer reviewed.

Data availability statement All data relevant to the study are included in the article or uploaded as online supplemental information. We do not have consent for data sharing from the study participants.

Open access This is an open access article distributed in accordance with the Creative Commons Attribution Non Commercial (CC BY-NC 4.0) license, which permits others to distribute, remix, adapt, build upon this work non-commercially, and license their derivative works on different terms, provided the original work is properly cited, appropriate credit is given, any changes made indicated, and the use is non-commercial. See: http://creativecommons.org/licenses/by-nc/4.0/.

\section{ORCID iDs}

Nathan Ashley Pearson http://orcid.org/0000-0002-1071-7529

Elizabeth Tutton http://orcid.org/0000-0003-3973-360X

\section{REFERENCES}

1 Poddubnyy D. Axial spondyloarthritis: is there a treatment of choice? Ther Adv Musculoskelet Dis 2013;5:45-54.

2 Sieper J, Poddubnyy D. Axial spondyloarthritis. Lancet 2017;390:73-84.

3 Raine C, Keat A. Axial spondyloarthritis. Medicine 2014;42:251-6.

4 Boonen A, Braun J, van der Horst Bruinsma IE, et al. ASAS/WHO ICF core sets for ankylosing spondylitis (as): how to classify the impact of as on functioning and health. Ann Rheum Dis 2010;69:102-7.

5 NASS. National ankylosing spondylitis Society: nass research priorities 2013-2018, 2013. Available: http://nass.co.uk/research/ nass-research-priorities/ [Accessed 11 Dec 2017].

6 Aissaoui N, Rostom S, Hakkou J, et al. Fatigue in patients with ankylosing spondylitis: prevalence and relationships with diseasespecific variables, psychological status, and sleep disturbance. Rheumatol Int 2012;32:2117-24. 
7 Haywood KL, Packham JC, Jordan KP. Assessing fatigue in ankylosing spondylitis: the importance of frequency and severity. Rheumatology 2014;53:552-6.

8 Farren W, Goodacre L, Stigant M. Fatigue in ankylosing spondylitis: causes, consequences and self-management. Musculoskeletal Care 2013;11:39-50.

9 Davies H, Brophy S, Dennis M, et al. Patient perspectives of managing fatigue in ankylosing spondylitis, and views on potential interventions: a qualitative study. BMC Musculoskelet Disord 2013;14:163.

10 Naegeli AN, Flood E, Tucker J, et al. The patient experience with fatigue and content validity of a measure to assess fatigue severity: qualitative research in patients with ankylosing spondylitis (as). Health Qual Life Outcomes 2013;11:192.

11 Mengshoel AM. Living with a fluctuating illness of ankylosing spondylitis: a qualitative study. Arthritis Rheum 2008;59:1439-44.

12 Mengshoel AM. Life strain-related tiredness and illness-related fatigue in individuals with ankylosing spondylitis. Arthritis Care Res 2010;62:1272-7.

13 Mortada M, Abdul-Sattar A, Gossec L. Fatigue in Egyptian patients with rheumatic diseases: a qualitative study. Health Qual Life Outcomes 2015;13:134. Available at.

14 Eilertsen G, Ormstad H, Kirkevold M, et al. Similarities and differences in the experience of fatigue among people living with fibromyalgia, multiple sclerosis, ankylosing spondylitis and stroke. $J$ Clin Nurs 2015;24:2023-34.

15 Smith J, Flowers P, Larkin M. Interpretative phenomenological analysis: theory, method and research, 2009.

16 Conrad P. The experience of illness: recent and new directions. Res Sociol Health Care 1987;6:1-31.

17 Sieper J, Rudwaleit M, Baraliakos X, et al. The assessment of spondyloarthritis International Society (ASAS) Handbook: a guide to assess spondyloarthritis. Ann Rheum Dis 2009;68 Suppl 2:ii1-44.

18 Garrett S, Jenkinson T, Kennedy LG, et al. A new approach to defining disease status in ankylosing spondylitis: the Bath ankylosing spondylitis disease activity index. J Rheumatol 1994;21:2286-91.

19 Calin A, Garrett S, Whitelock H, et al. A new approach to defining functional ability in ankylosing spondylitis: the development of the Bath ankylosing spondylitis functional index. J Rheumatol 1994;21:2281-5.

20 Zigmond AS, Snaith RP. The hospital anxiety and depression scale. Acta Psychiatr Scand 1983;67:361-70.

21 Rudwaleit M, van der Heijde D, Landewé R, et al. The development of assessment of spondyloarthritis International Society classification criteria for axial spondyloarthritis (Part II): validation and final selection. Ann Rheum Dis 2009;68:777-83.

22 QSR International Pty Ltd. NVivo qualitative data analysis software, 2014.

23 Yardley L. Dilemmas in qualitative health research. Psychol Health 2000:15:215-28.

24 Lerdal A. A theoretical extension of the concept of energy through an empirical study. Scand J Caring Sci 2002;16:197-206.

25 Lerdal A. A concept analysis of energy. its meaning in the lives of three individuals with chronic illness. Scand J Caring Sci 1998;12:3-10.

26 Eshragh J, Dhruva A, Paul SM, et al. Associations between neurotransmitter genes and fatigue and energy levels in women after breast cancer surgery. J Pain Symptom Manage 2017;53:67-84.

27 Aouizerat BE, Gay CL, Lerdal A, et al. Lack of energy: an important and distinct component of HIV-related fatigue and daytime function. J Pain Symptom Manage 2013;45:191-201.

28 Jacobson J, Ju A, Baumgart A, et al. Patient perspectives on the meaning and impact of fatigue in hemodialysis: a systematic review and thematic analysis of qualitative studies. Am J Kidney Dis 2019;74:179-92.

29 Horigan AE, Schneider SM, Docherty S, et al. The experience and self-management of fatigue in patients on hemodialysis. Nephrol Nurs J 2013;40:113-22.

30 Anon. Fatigue Guidelines Development Panel of the Multiple Sclerosis Council for Clinical Practice Guidelines. Fatigue and Multiple Sclerosis. Evidence-Based Management Strategies for Fatigue in Multiple Sclerosis. Washington, DC: Paralyzed Veterans of America, 1998.
31 Lerdal A, Kottorp A, Gay CL, et al. Lee fatigue and energy scales: exploring aspects of validity in a sample of women with HIV using an application of a Rasch model. Psychiatry Res 2013;205:241-6.

32 Fitzpatrick C, Connolly D, O'Shea F. 222. exploring the impact of fatigue on activity levels and quality of life in people with ankylosing spondylitis. Rheumatology2015;54:1135-6.

33 Scott JA, Lasch KE, Barsevick AM, et al. Patients' experiences with cancer-related fatigue: a review and synthesis of qualitative research. Oncol Nurs Forum 2011;38:E191-203.

34 Lee KA, Gay C, Portillo CJ, et al. Symptom experience in HIV-infected adults: a function of demographic and clinical characteristics. J Pain Symptom Manage 2009;38:882-93.

35 Hewlett S, Cockshott Z, Byron M, et al. Patients' perceptions of fatigue in rheumatoid arthritis: overwhelming, uncontrollable, ignored. Arthritis Rheum 2005;53:697-702

36 Nikolaus S, Bode C, Taal E, et al. New insights into the experience of fatigue among patients with rheumatoid arthritis: a qualitative study. Ann Rheum Dis 2010;69:895-7.

37 Feldthusen C, Björk M, Forsblad-d'Elia H, et al. Perception, consequences, communication, and strategies for handling fatigue in persons with rheumatoid arthritis of working age--a focus group study. Clin Rheumatol 2013;32:557-66.

38 Garrido-Cumbrera M, Hillmann O, Mahapatra R, et al. Improving the management of psoriatic arthritis and axial spondyloarthritis: roundtable discussions with healthcare professionals and patients. Rheumatol Ther 2017;4:219-31.

39 Repping-Wuts $\mathrm{H}$, Hewlett $\mathrm{S}$, van Riel $\mathrm{P}$, et al. Fatigue in patients with rheumatoid arthritis: British and Dutch nurses' knowledge, attitudes and management. J Adv Nurs 2009;65:901-11.

40 Sacristán JA, Dilla T, Díaz-Cerezo S, et al. Patient-Physician discrepancy in the perception of immune-mediated inflammatory diseases: rheumatoid arthritis, psoriatic arthritis and psoriasis. A qualitative systematic review of the literature. PLoS One 2020;15:e0234705.

41 Zhao S, Thong D, Miller N, et al. The prevalence of depression in axial spondyloarthritis and its association with disease activity: a systematic review and meta-analysis. Arthritis Res Ther 2018;20:140.

42 Kiltz U, Wendling D, Braun J. ASAS Health Index: The "All in One" for Spondyloarthritis Evaluation? J Rheumatol 2020;47:1457-60.

43 Marks R. Self-Efficacy and arthritis disability: an updated synthesis of the evidence base and its relevance to optimal patient care. Health Psychol Open 2014;1:205510291456458.

44 van der Heijde D, Ramiro S, Landewé R, et al. 2016 update of the ASAS-EULAR management recommendations for axial spondyloarthritis. Ann Rheum Dis 2017;76:978-91.

45 Taurog JD, Chhabra A, Colbert RA. Ankylosing spondylitis and axial spondyloarthritis. N Engl J Med 2016;374:2563-74.

46 Millner JR, Barron JS, Beinke KM, et al. Exercise for ankylosing spondylitis: an evidence-based consensus statement. Semin Arthritis Rheum 2016;45:411-27.

47 Sveaas SH, Bilberg A, Berg IJ, et al. High intensity exercise for 3 months reduces disease activity in axial spondyloarthritis (axSpA): a multicentre randomised trial of 100 patients. Br J Sports Med 2020;54:292-7.

48 Moore RA, Straube S, Aldington D. Pain measures and cut-offs - 'no worse than mild pain' as a simple, universal outcome. Anaesthesia 2013;68:400-12.

49 Bedaiwi M, Sari I, Thavaneswaran A, et al. Fatigue in ankylosing spondylitis and Nonradiographic axial spondyloarthritis: analysis from a longitudinal observation cohort. J Rheumatol 2015;42:2354-60.

50 Sieper J, van der Heijde D, der HDvan. Review: Nonradiographic axial spondyloarthritis: new definition of an old disease? Arthritis Rheum 2013;65:543-51.

51 Danve A, Deodhar A. Axial spondyloarthritis in the USA: diagnostic challenges and missed opportunities. Clin Rheumatol 2019;38:625-34

52 Burgos-Varga R, Wei JC-C, Rahman MU, et al. The prevalence and clinical characteristics of nonradiographic axial spondyloarthritis among patients with inflammatory back pain in rheumatology practices: a multinational, multicenter study. Arthritis Res Ther 2016;18:132. 